\title{
PENGENALAN PEMBELAJARAN AKUNTANSI YANG MENYENANGKAN DENGAN IMAJINASI DAN QUIZLET PADA SMA KA BASYARIYAH KABUPATEN MADIUN
}

\author{
Elana Era Yusdita ${ }^{1 *}$, Dwi Astutik ${ }^{2}$, Sherlyana Juwita Ningrum $^{3}$ \\ ${ }^{1 *}$ Universitas PGRI Madiun \\ elaradita@gmail.com \\ ${ }^{2,3}$ Universitas PGRI Madiun \\ 22dwiastutik98.da@gmail.com, ${ }^{3}$ sherlyanajuwita@gmail.com
}

\begin{abstract}
ABSTRAK
Kondisi kelas yang kondusif jarang didapati di salah satu kelas di SMA KA Basyariyah. Apalagi materi yang dipajari adalah jurnal penyesuaian yang dipandang agak sulit daripada jurnal biasa. Tujuan pengabdian kepada masyarakat ini adalah mengenalkan cara belajar akuntansi yang menyenangkan dengan imajinasi dan Quizlet pada SMA KA Basyariyah Kabupaten Madiun. Dosen dan mahasiswa Pendidikan Akuntansi Universitas PGRI Madiun berkolaborasi menciptakan suasana menyenangkan pada saat pembelajaran. Keaktifan siswa diarahkan kepada hal positif, yaitu evaluasi pembelajaran secara berkelompok menggunakan Quizlet. Pemahaman dan perilaku peserta didik berubah setelah belajar dengan cara ini. Mahasiswa pendidikan akuntansi juga mendapatkan pengalaman cara menguasai kelas sekaligus mengajar.
\end{abstract}

Kata Kunci: media pembelajaran; perilaku peserta didik; jurnal penyesuaian; pendidikan akuntansi

\section{ABSTRACT}

A conducive class is rarely found in one of the classes at SMA KA Basyariyah. Moreover, the material being taught is an adjusting journal, which is considered a bit difficult than making an ordinary journal. The aim of this community service is to introduce a fun way of learning accounting with imagination and Quizlet at SMA KA Basyariyah, Madiun Regency. Lecturers and students of the PGRI Madiun University Accounting Education collaborate to create a pleasant atmosphere during learning. Student activity is directed to positive things, namely the evaluation of learning in groups using Quizlet. Learners' understanding and behavior change after learning in this way. Accounting education students also gain experience on how to master classes and teach at the same time.

Keywords: learning media; student behavior; adjusting journal entry; accounting education 


\section{PENDAHULUAN}

Bagi sebagian besar pendidik, kelas kondusif adalah kondisi ideal untuk pembelajaran. Namun, salah satu kelas di SMA Kyai Ageng Basyariyah diisi oleh anakanak yang memiliki imajinasi dan energi berlebih sehingga tampak tidak fokus dalam mengikuti pembelajaran kelas. Saat tim pengabdian Pendidikan Akuntansi UNIPMA berkunjung untuk memperkenalkan Quizlet, ternyata didapati beberapa siswa harus dibuat tenang dengan tenaga ekstra.

Mengetahui kondisi tersebut, tim pengabdian berusaha memanfaatkan tenaga dan pikiran siswa-siswa tersebut ke kegiatan positif. Materi yang sedang diajarkan adalah jurnal penyesuaian. Materi ini cukup menantang karena minat dan pemahaman siswa pada materi jurnal penyesuaian berujung pada kesulitan belajar, apalagi jika metode pembelajaran kurang inovatif (Wulandari et al, 2014). Siswa yang hiperaktif pada saat awal pembelajaran menjadi pasif pada saat tanya jawab. Hal serupa ditemukan pada siswa SMA Bina Cipta Palembang yang mempelajari jurnal penyesuaian (Putri, 2018). Sedangkan saat ada teman yang berisik, seorang siswa bisa jadi akan terganggu konsentrasinya (Wahyuningsih et al., 2015). Meskipun milenial secara perorangan disuguhi pembelajaran berbasis teknologi, konsentrasinya masih ada yang dapat terganggu yang mengarah pada kesulitan belajar (Pratama et al., 2020).

Sebelum masuk ke materi utama yang dijelaskan oleh mahasiswa HIMADIKSI UNIPMA, dosen memberikan gambaran komprehensif kaitan materi identifikasi transaksi - membuat jurnal - buku besar - laporan keuangan - jurnal penyesuaian. Sedangkan untuk evaluasi pembelajaran menggunakan Quizlet yang harus dikerjakan secara tim. Media ajar yang tepat akan memotivasi dan membuat siswa fokus terhadap materi yang diajarkan (Suprianti, 2018). Selain itu, generasi milenial yang suka dengan aplikasi, bermain handphone, dapat diarahkan untuk berfikir kritis dengan Quizlet (Sari, 2019).

Hikmah (2017) menggunakan Quizlet untuk menghafalkan dan mengetahui ejaan yang benar dalam pembelajaran bahasa asing pada mahasiswa Teknik Informatika STT Nurul Jadid Probolinggo. Sementara itu, pada bidang ilmu akuntansi, belum ada pendidik yang memanfaatkan untuk menyelesaikan masalah pembelajaran akuntansi, khususnya jurnal penyesuaian. 
Tujuan pengabdian kepada masyarakat ini adalah mengenalkan cara belajar akuntansi yang menyenangkan dengan imajinasi dan Quizlet pada SMA KA Basyariyah Kabupaten Madiun. Selain itu, diharapkan kegiatan pengabdian ini dapat menjadi masukan bagi kegiatan pembelajaran pendidikan akuntansi mengenai cara belajar yang menyenangkan bagi siswa. Mahasiswa pendidikan akuntansi juga belajar cara menghadapi peserta didik dengan baik dan benar.

\section{METODE}

Tim pengabdian Pendidikan Akuntansi UNIPMA terdiri dari dua mahasiswa dan satu dosen sebagai pemateri, serta tujuh mahasiswa yang berperan sebagai panitia yang mendukung keberhasilan program. Pengabdian diawali dengan survey dan pengurusan izin pelaksanaan kegiatan pada September 2019, sedangkan pelaksanaan dilakukan selama satu hari di SMA Kyai Ageng Basyariyah pada tanggal 23 September 2019. Peserta pengabdian adalah siswa-siswi kelas XII IPS 2. Runtutan kegiatan yang dialakukan adalah: (1) survey lokasi, (2) permintaan izin kepada sekolah, (3) pelaksanaan program, (4) evaluasi kegiatan. Pada saat pelaksanaan program, materi yang disampaikan adalah pemahaman komprehensif siklus akuntansi, pencatatan dan penghitungan jurnal penyesuaian, dan evaluasi pembelajaran secara tim menggunakan Quizlet. Sarana prasarana tambahan yang dibutuhkan adalah smartphone dan kuota internet. Hadiah untuk pemenang Quizlet serta souvenir untuk pemenang juga disediakan oleh tim pengabdian.

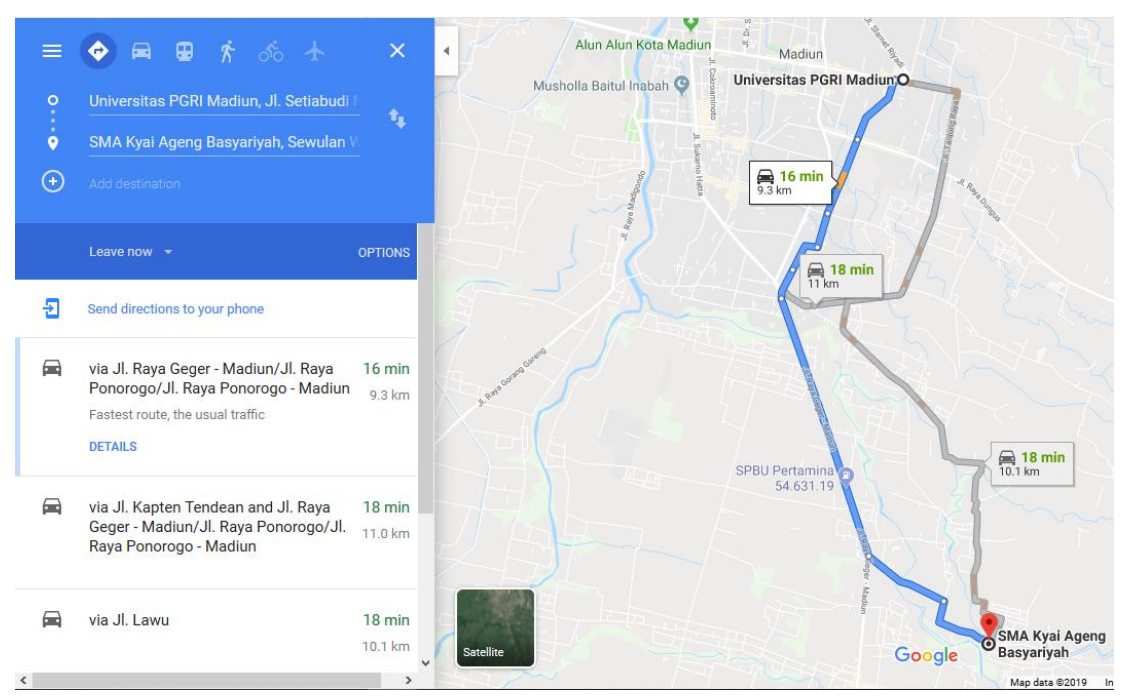

Gambar 1. Peta Lokasi Kegiatan Pengabdian 


\section{HASIL DAN PEMBAHASAN}

Pada saat pelaksanaan, kondisi kelas sedikit tidak kondusif. Terlihat bahwa pendisiplinan dilakukan dengan hukuman dan perintah untuk tetap diam. Pada saat salam pembuka kegiatan pengabdian, siswa masih bisa diam. Pada saat masuk penjelasan materi, sebagian anak mulai ramai, sedangkan sisanya tidak terlalu semangat untuk mengikuti pembelajaran. Solusinya adalah penjelasan oleh mahasiswa dihentikan dan dosen memberi penjelasan komprehensif tentang identifikasi transaksi sampai dengan penjurnalan penyesuaian tentang kejadian sehari-hari. Metode dialog digunakan agar pembelajaran tidak berjalan satu arah atau berpusat pada pendidik. Ilustrasinya adalah sebagai berikut:

Dosen : "Ada yang tau kaitan jurnal penyesuaian dengan materi sebelumnya bagaimana?"

Siswa $\quad:($ diam $)$

Dosen : "Lho, kok diam? Paham yang dipelajari selama ini apa tidak?"

Siswa : (diam)

Dosen : "Oke, pikirkan jurnal adalah sesuatu yang mudah. Nama akun bisa kita atur, jangan diingat yang ada di buku. Saya beri contoh jurnal untuk kejadian sehari-hari. Ingat, yang dijurnal adalah kejadian ekonomi, kalau bukan jangan dijurnal. Misalnya, kamu bangun pagi...

Salah 1 siswa $\quad$ : “...kuterus mandi..” (yang lain tertawa)

Dosen : "Lho pinternyaaa... memang begitu yang benar, setelah bangun pagi, langsung mandi.. (suasana tenang kembali). Nah, tiba-tiba sabunnya habis. Harus ke toko depan rumah buat beli. Kira-kira ini bisa dijurnal apa tidak?"

Siswa : "Iyaaa..."

Dosen : "Bagaimana jurnalnya?"

Siswa : (diam)

Dosen : "Kalau kita beli sabun, apa yang bertambah di kitanya?"

Siswa : "Sabuuun."

Dosen : "Kalau bayarnya kontan, nggak ngutang... Berarti apa yang 
Siswa

Dosen

Bersama-sama

Dosen

Siswa

Dosen

Siswa

Dosen

Siswa

Dosen

Siswa

Dosen

Siswa

Dosen

Siswa berkurang di kita?"

: "Uang.. eh, kas.."

: "Nah, nama akun bisa kita pilih sesuka kita untuk akuntansi yang tidak terikat peraturan. Kalau mau dinamai "duit" atau "uang saku" juga boleh, asalkan nama akunnya konsisten agar bisa rekapan, kumpul jadi satu di buku besar. Eh, berarti bagaimana jurnalnya?"

: "Debit pada sabun, kredit pada kas."

: “Gampang kan? Terus lanjut pada buku besar, ternyata kamu bolak balik belanja di toko itu, ada yang utang. Hari ini utang Rp10.000,-, kemarin ada utang Rp50.000,-, terus tiba-tiba sore ini kamu diberi uang oleh orang tua sebesar Rp30.000,-, lumayan buat bayar utang. Biar nggak lupa dan tau saldo terakhir utangnya, diapain?"

: "Dicatat, dikumpulkan jadi satu."

: "Ya, itu namanya pencatatan pada buku besar. Jadi yang akunnya sama dikumpulkan jadi satu biar tau saldo akhirnya. Akun-akun tadi kalau sudah tau saldo akhirnya dikumpulkan lagi jadi satu, namanya neraca saldo."

: (beberapa mengangguk paham)

: "Kadang akhir periode pas dihitung lagi ada yang berubah, misalnya persediaan sabun menurut catatan ada 10 buah, ternyata 2 buah sabun dimakan tikus. Berarti butuh apa?"

: "Disesuaikan.."

: "Nah, itu pakai jurnal penyesuaian. Jurnalnya bagaimana? Apa yang berkurang?"

: "Sabun."

: "Dimana letaknya? Debit atau kredit?"

: "Kredit.."

: “Bagus..Lalu, apa yang ada di sebelah debit?” 
Dosen

Siswa
: "Bisa kita beri nama akun Beban Penyusutan Sabun. Setelah itu, bisa kita jumlah atau kurangkan menjadi neraca saldo setelah penyesuaian. Setelah itu baru dikelompokkan mana akun yang masuk Laba/Rugi, mana yang masuk Laporan Posisi Keuangan atau Neraca."

: "Iya, bu.."

Cara tersebut dapat dilakukan untuk mengatasi anak-anak yang berlebih tenaga dan imajinasinya, sering kita sebut "troublemaker". Padahal jika dimanfaatkan secara positif, mereka dapat duduk tenang dan memperhatikan. Kuncinya adalah jika pendidik mulai dibully oleh siswa, pendidik harus tetap tenang, tidak merendah dan tidak juga meninggi, posisikan diri sebagai sahabat yang bisa mereka ajak bersenang-senang sambil belajar di kelas.

Setelah suasana kelas dapat dikendalikan, barulah mahasiswa memberikan penjelasan tentang contoh soal jurnal penyesuaian, beserta langkah pengerjaannya. Suasana pembelajaran dapat dilihat pada Gambar 2 dan 3.

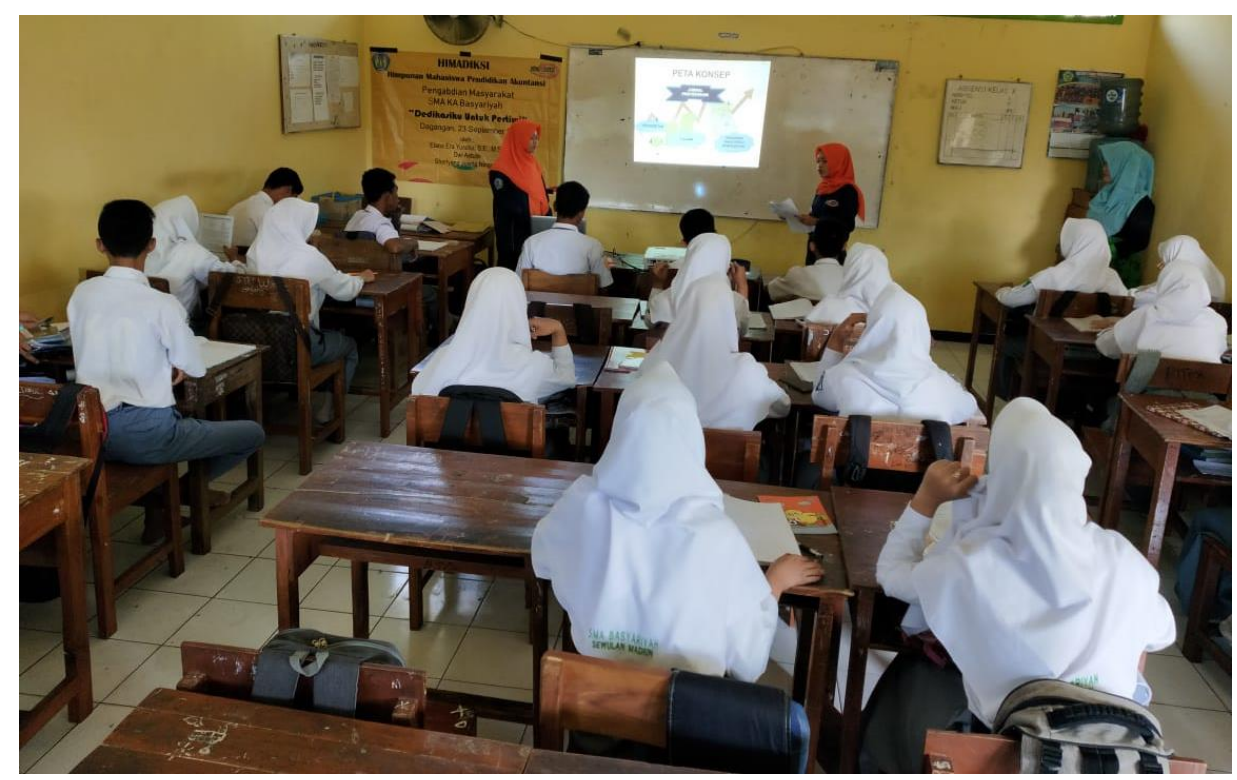

Gambar 2. Penyampaian Materi Jurnal Penyesuaian di Kelas XII IPS 2 


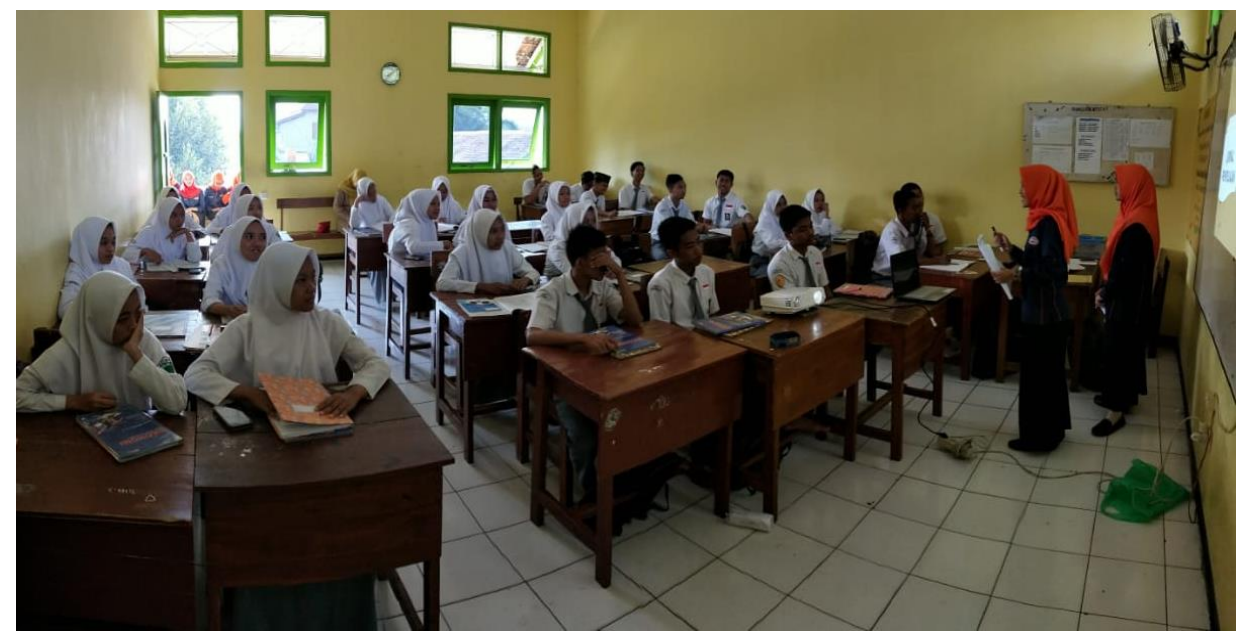

Gambar 3. Suasana Pembelajaran di Kelas XII IPS 2

Setelah penjelasan materi selesai, tim pengabdian mengajak siswa-siswa untuk membentuk kelompok yang terdiri dari 3 siswa, serta mengambil smartphone masingmasing untuk mengakses Quizlet. Evaluasi yang dilakukan mengenai akuntansi serta tentang institusi tim pengabdian untuk cek apakah mereka konsentrasi mendengarkan penjelasan dari perkenalan sampai materi jurnal penyesuaian. Soal Quizlet ada pada gambar 4.
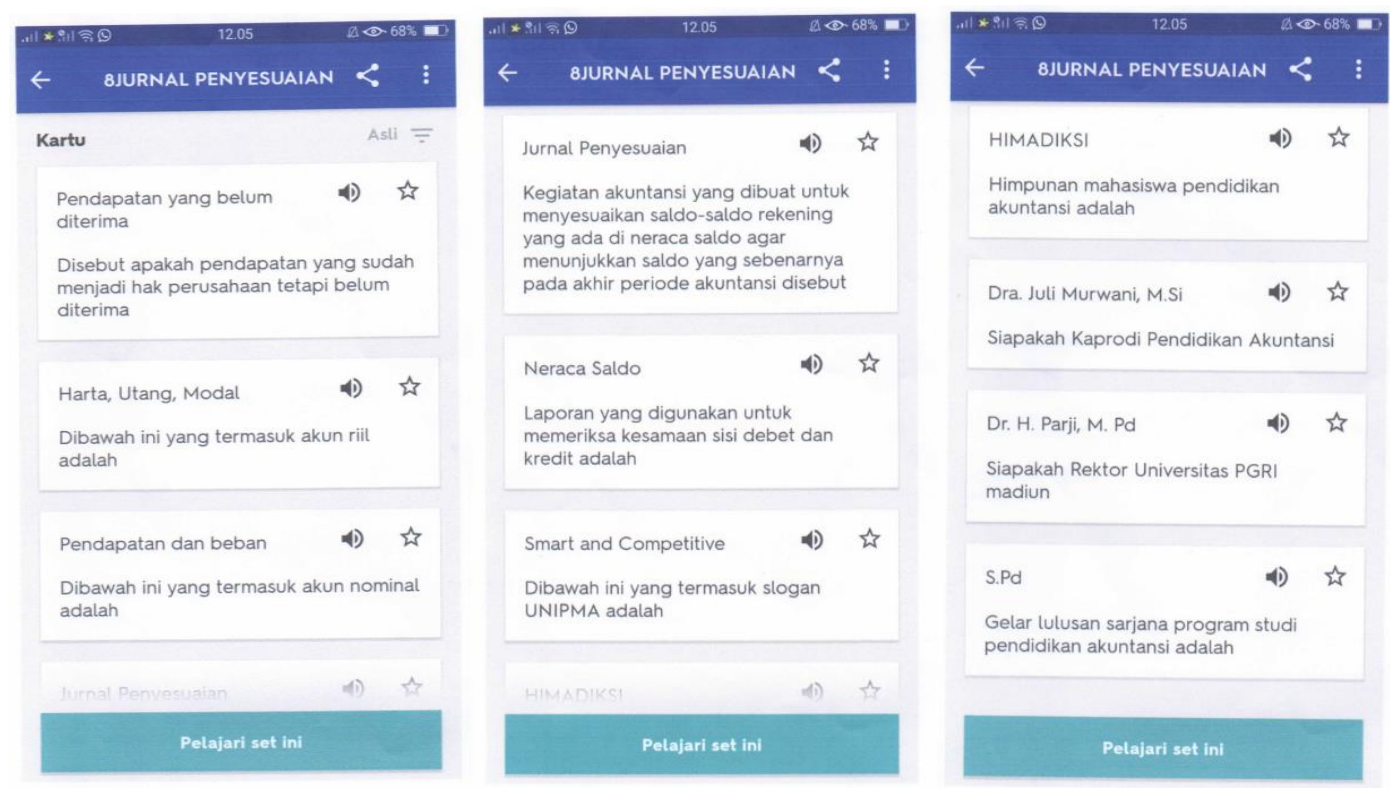

Gambar 4. Soal dan Kunci Jawaban pada Quizlet 
Kendala yang dihadapi adalah akses internet lancar yang tidak dimiliki oleh setiap anak, jadi tim pengabdian menyiapkan kuota internet untuk tethering ke semua smartphone yang membutuhkan. Kondisi mendadak ramai ketika kuis sudah dimulai karena setiap anak harus mendukung timnya menjawab kuis, dan setiap tim diadu kecepatannya yang dapat disaksikan bersama melalui LCD. Setiap anak diajak fokus untuk membuat timnya menang.

Ketika pemenang sudah ada, kuis dihentikan. Anggota tim yang menang dipanggil ke depan kelas untuk menerima hadiah dari tim pengabdian (Gambar 5). Kenangkenangan juga dibagikan ke setiap anak yang sudah berpartisipasi pada pembelajaran hari ini.

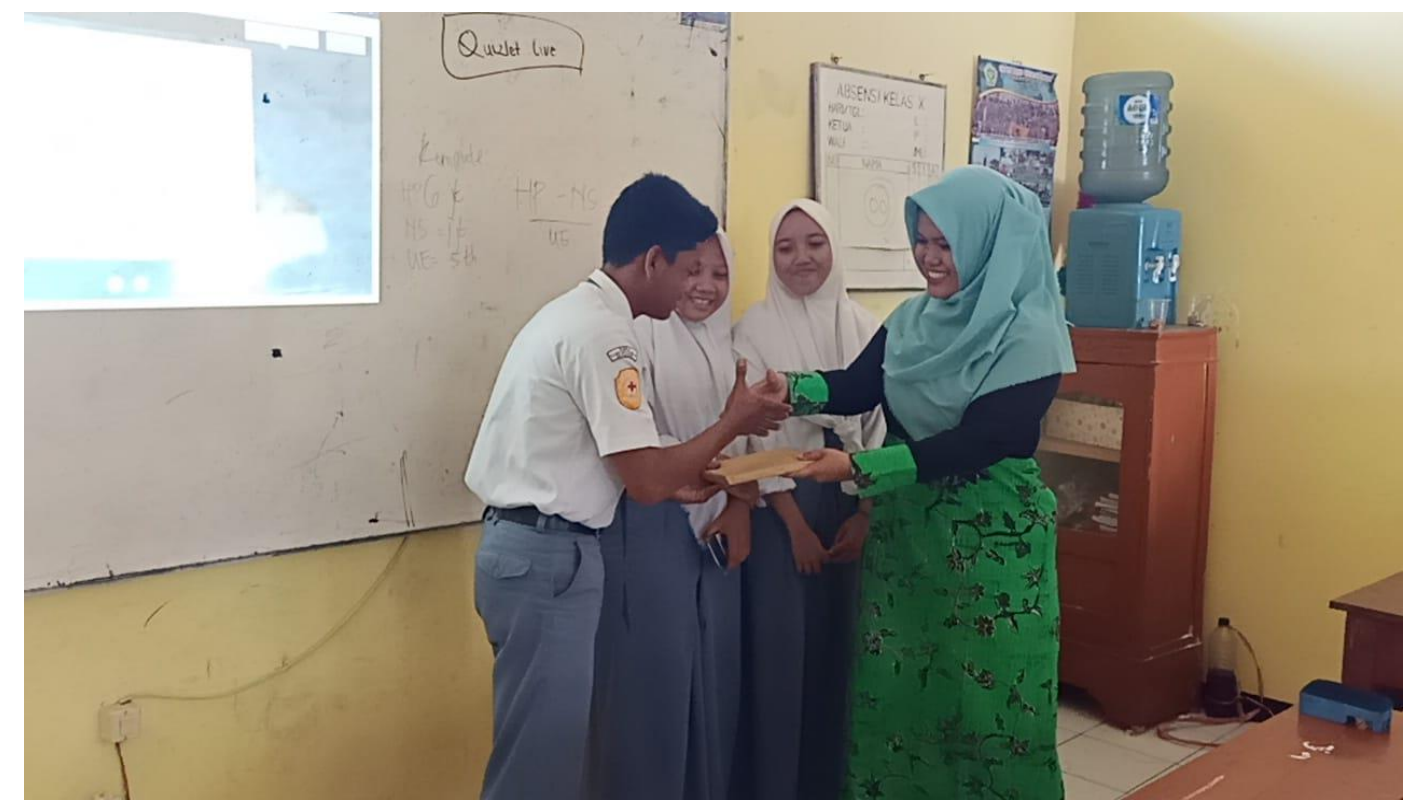

Gambar 5. Pemberian Hadiah untuk Pemenang Quizlet

Siswa-siswa yang ditanyai langsung pendapatnya mengenai pembelajaran hari itu mengatakan bahwa metodenya menyenangkan. Bagi siswa kelas XII IPS 2, hari itu adalah pertama kalinya menggunakan Quizlet. Cara pendidik memperlakukan anak didik juga mempengaruhi perilaku anak didik itu sendiri. Perubahan perilaku tampak antara sebelum dan sesudah pengabdian. Pada pagi hari, beberapa siswa di kelas tersebut yang melihat tim pengabdian datang, sibuk melakukan suitan dan sorak sorai. Namun, setelah selesai, mereka mengantarkan kepulangan tim pengabdian dengan sopan dan berkata tidak ingin ditinggal. Hal ini juga menjadi pengalaman bagi 
mahasiswa untuk mengetahui cara menaklukkan kelas yang kurang kondusif ketika mengajar serta mencari media pembelajaran yang sesuai dengan materi dan karakteristik peserta didik.

\section{SIMPULAN DAN SARAN}

Menggunakan imajinasi dan Quizlet dapat menaklukkan kelas yang tidak kondusif serta menambah pemahaman peserta didik pada materi akuntansi, khususnya jurnal penyesuaian. Tujuan utama pendidik tidak hanya transfer ilmu di kelas, namun juga nilai kebaikan. Perubahan perilaku adalah salah satu tujuan pendidikan. Keterbatasan pengabdian ini adalah kesempatan yang tersedia hanya satu hari untuk mengajar serta kurangnya akses internet jika ingin memanfaatkan pembelajaran berbasis teknologi. Tim pengabdian mendatang dapat memanfaatkan program yang disediakan Kemenristekdikti untuk mengenalkan teknologi dan media pembelajaran agar pembelajaran semakin menyenangkan, dan tidak terbatas pada akuntansi saja.

\section{UCAPAN TERIMA KASIH}

Terima kasih kepada SMA Kyai Ageng Basyariyah, khususnya Kepala Sekolah, Bapak H. Ahmad Nuzul, S.Pd. yang memberikan kesempatan kepada tim pengabdian Pendidikan Akuntansi Universitas PGRI Madiun untuk mengajar. Tim pengabdian Pendidikan Akuntansi UNIPMA: Prisilia Kusuma Dewi, Mafula Nurul Hidajati, Anisa Iswara Dinata, Nada Fadia Hayya, Nur ' Asari Tyasningum, Tika Putri Lestari, Ida Nur Indah Filaili yang mendukung perencanaan dan pelaksanaan pengabdian sehingga berjalan lancar.

\section{DAFTAR PUSTAKA}

Hikmah, D. (2017). Penggunaan Quizlet Sebagai Media Pengenalan Informatics Terms. Seminar Nasional Ilmu Terapan (SNITER) 2017 - Universitas Widya Kartika, B06-1 - B06-6.

Pratama, H. O., Utomo, S. W., \& Yusdita, E. E. (2020). Analisis Kesulitan Belajar MYOB pada Mahasiswa Pendidikan Akuntansi. Wahana: Jurnal Ekonomi, Manajemen, dan Akuntansi 23 (1), 81-97. 
Putri, S. P. (2018). Analisis Kesulitan Belajar Siswa Dalam Menyelesaikan Soal Jurnal Penyesuaian Pada Mata Pelajaran Ekonomi. Jurnal Neraca 2(2), 97-107.

Sari, D. E. (2019). Quizlet: Aplikasi Pembelajaran Berbasis Smartphone Era Generasi Milenial. Jurnal Pendidikan dan Ilmu Sosial 29 (1), 9-15.

Suprianti, G. A. P. (2018). Pelatihan Dan Bimbingan Teknis Pembuatan Media Ajar Inovatif Berbasis Internet Bagi Guru-Guru Bahasa Inggris. Jurnal Widya Laksana 7(1), 1-9.

Wahyuningsih, T., Parijo, \& Rosyid, R. (2015). Faktor yang Mempengaruhi Kesulitan Belajar Siswa pada Mata Diklat Siklus Akuntansi Kelas XI di SMK. Jurnal Pendidikan dan Pembelajaran Khatulistiwa 4(9), 1-13.

Wulandari, M., Djaja, S., \& Suharso, P. (2014). Analisis Kesulitan Belajar Akuntansi Pada Materi Jurnal Penyesuaian (Studi Kasus Pada Siswa Kelas XI IPS di SMA Negeri 1 Pakusari Tahun Ajaran 2013-2014). Jurnal EDUKASI UNEJ I (2), 2327. 